\title{
Bayesian probabilistic reconstruction of metamorphic $P-T$ paths using inclusion geothermobarometry
}

\author{
Tatsu Kuwatani ${ }^{*}, \dagger$, Kenji Nagata ${ }^{* *}, \dagger$, Kenta YoshidA $^{*}$, Masato OKadA $^{* * *}$ and Mitsuhiro Toriumi ${ }^{*}$ \\ *Japan Agency for Marine-Earth Science and Technology (JAMSTEC), Yokosuka 237-0061, Japan \\ ${ }^{* *}$ Artificial Intelligence Research Center, National Institute of Advanced Industrial Science and Technology (AIST), \\ Tokyo 135-0064, Japan \\ ${ }^{* * *}$ Graduate School of Frontier Sciences, The University of Tokyo, Kashiwa 277-8561, Japan \\ ${ }^{\dagger}$ PRESTO, Japan Science and Technology Agency (JST), Kawaguchi 332-0012, Japan
}

\begin{abstract}
Geothermometry and geobarometry are used to study the equilibration of mineral inclusions and their zoned host minerals, which provide information on the $P-T$ conditions of inclusions at the time of their entrapment. However, reconstructing detailed $P-T$ paths remains difficult, owing to the sparsity of inclusions suitable for geothermometry and geobarometry. We developed a stochastic inversion method for reconstructing precise $P-T$ paths from chemically zoned structures and inclusions using the Markov random field (MRF) model, a type of Bayesian stochastic method often used in image restoration. As baseline information for $P-T$ path inversion, we introduce the concepts of pressure and temperature continuity during mineral growth into the MRF model. To evaluate the proposed model, it was applied to a $P-T$ inversion problem using the garnet-biotite geothermometer and the garnet- $\mathrm{Al}_{2} \mathrm{SiO}_{5}$-plagioclase-quartz geobarometer for mineral compositions from published datasets of host garnets and mineral inclusions in pelitic schist. Our method successfully reconstructed the $P-T$ path, even after removing a large part of the inclusion dataset. In addition, we found that by using a probability distribution of the most probable $P-T$ path, rather than a single solution, an objective discussion of the validity of the thermodynamic analysis is possible.
\end{abstract}

Keywords: $P-T$ path, Chemical zoning, Mineral inclusion, Bayesian estimation, Data-driven approach

\section{INTRODUCTION}

Chemically zoned minerals provide fundamental information about the metamorphic history that the metamorphic rock has undergone. Estimations of precise and continuous $P-T$ paths can be key for constructing models of tectonics and material recycling at past and present-day plate boundaries (e.g., Spear, 1993; Omori et al., 2009; Konrad-Schmolke and Halama, 2014). On the basis of thermodynamic equilibrium, the $P-T$ conditions of metamorphic rocks can be estimated using conventional geothermobarometry that involves cation exchange and nettransfer reactions (e.g., Spear, 1993), unless the homogenization of the compositional zoning has taken place owing to volume diffusion (e.g., Yardley, 1977; Okudaira, 1996).

doi:10.2465/jmps. 170923

T. Kuwatani, kuwatani@jamstec.go.jp Corresponding author
If suitable mineral assemblages for geothermometry and geobarometry are present in the same horizon of a chemically zoned mineral, the $P-T$ conditions at a specific moment of the metamorphic event can be estimated (with so-called inclusion geothermobarometry). Furthermore, if a series of analysis points can be obtained, an approximate $P-T$ path can be constructed by connecting these points (e.g., St-Onge, 1987; Whitney and Ghent, 1993; Jones, 1994; Hoisch et al., 2002; Vignaroli et al., 2005; Burenjargal et al., 2012). However, such fortunate cases are rare, and consequently it is not always possible to construct a continuous $P-T$ path based on inclusion geothermobarometry.

Gibbs' method, a differential thermodynamic $P-T$ inversion method, is a powerful approach to overcome this difficulty, in which a persistent equilibrium between coexisting minerals can be recognized, and the compositional trends of zoned minerals are translated into continuous $P$ $T$ paths (e.g., Spear and Selverstone, 1983; Spear, 1993; 
Okamoto and Toriumi, 2001; Inui and Toriumi, 2002). However, a sufficient number of coexisting minerals is required to compensate for thermodynamic variance; thus, the utility of Gibbs' method is limited in comparison with ordinary geothermobarometry. Recently, isopleth calculations have been employed to estimate the $P-T$ conditions of a specific moment or continuous path, based on the ubiquitous use of thermodynamic calculations at a fixed bulk composition-i.e., a $P-T$ pseudosection or isochemical phase diagram (e.g., Massonne, 2011; Meyer et al., 2014). However, $P-T$ path estimations with isopleths of zoned minerals are limited to special cases where the effective bulk composition cannot be changed during metamorphic crystallization. Thus, for deterministic methodologies, it is difficult to estimate continuous $P-T$ paths, owing to geological uncertainty and insufficient information.

We propose a method for probabilistic estimations of $P-T$ paths using a Bayesian stochastic approach, rather than common deterministic approaches. Using a probabilistic methodology, we deal with various uncertainties, including those arising from compositional noise and the paucity of suitable inclusions. Recently, we applied the Markov random field (MRF) model, a Bayesian stochastic model that is often used in image analysis (e.g., Geman and Geman, 1984; Tanaka, 2002; Bishop, 2006) for various inversion problems in earth sciences (Kuwatani et al., 2012, 2014a, 2014b). In metamorphic petrology, Kuwatani et al. (2012) applied the MRF model to Gibbs' method, which assumes chemical equilibrium among all minerals. In this study, we apply the MRF model to inclusion geothermobarometry in order to construct a more widely applicable method for estimating continuous $P-T$ paths. The proposed method can probabilistically reconstruct $P-T$ paths even when there is a paucity of suitable inclusion assemblages. Using the Markov chain Monte Carlo sampling algorithm (Metropolis et al., 1953; Mosegaard and Tarantola, 1995), we can also quantitatively evaluate the uncertainties arising from measurement errors of chemical compositions and calibration errors of geothermobarometers.

In what follows, we first briefly describe inclusion geothermobarometry. We then propose a probabilistic formulation of $P-T$ path inversion using inclusion geothermobarometry, by employing the MRF model. In order to test the validity and effectiveness of the proposed method, we show examples of $P-T$ path inversion using the garnet-biotite geothermometer and garnet- $\mathrm{Al}_{2} \mathrm{SiO}_{5}{ }^{-}$ quartz-plagioclase geobarometer and applying these to well-investigated natural pelitic schists in the Wopmay Orogen, Canada, using a published dataset (St-Onge, 1987). Finally, we discuss the strengths and usability of the probabilistic approach for $P-T$ path estimations.

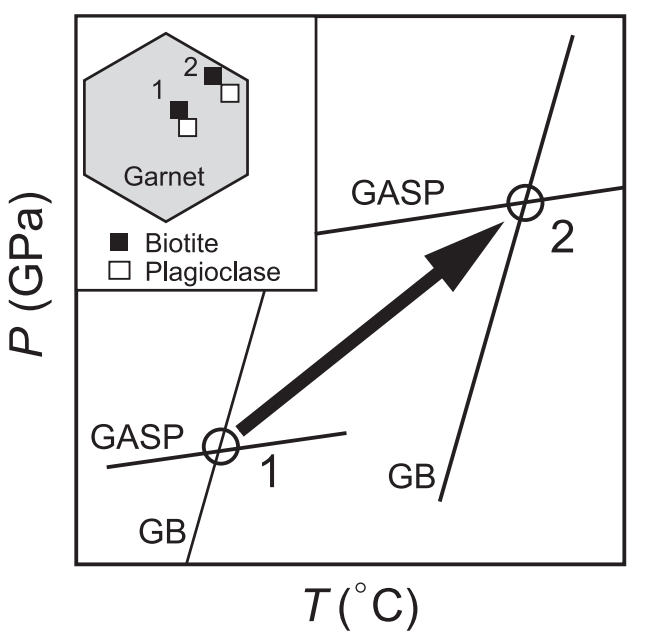

Figure 1. Schematic $P-T$ path reconstruction using inclusion geothermobarometry. GB and GASP indicate the garnet-biotite geothermometer and the garnet- $\mathrm{Al}_{2} \mathrm{SiO}_{5}$-plagioclase-quartz geobarometer, respectively.

\section{METHOD}

\section{Inclusion geothermobarometry}

We consider a situation in which a host garnet contains mineral inclusions suitable for geothermometers and geobarometers. The garnet-biotite geothermometer and the garnet- $\mathrm{Al}_{2} \mathrm{SiO}_{2}$-plagioclase-quartz (GASP) geobarometer were used in this study, because they are the most widely used systems in studies employing geothermobarometry (Fig. 1). Needless to say, any geothermometer/geobarometer pair can be used with the proposed method. In general form, the selected geothermometer and geobarometer can be written for measurement point $i$ as follows:

$$
f_{\text {Grt-Bt }}\left(P_{i}, T_{i}, X_{i}^{\mathrm{Grt}} s, X_{i}^{\mathrm{Bt}} s\right)=0
$$

and

$$
f_{\mathrm{GASP}}\left(P_{i}, T_{i}, X_{i}^{\mathrm{Grt}} s, X_{i}^{\mathrm{Bt}} s\right)=0
$$

where $P_{i}, T_{i}$, and $X_{i S}$ are the pressure, temperature, and composition of the host garnet (Grt) and the inclusion minerals biotite $(\mathrm{Bt})$ and plagioclase $(\mathrm{Pl})$ for measurement point $i$, respectively. In this study, the actual form of $f_{\text {Grt-Bt }}$ follows Ferry and Spear (1978), whereas that of $f_{\mathrm{GASP}}$ follows Koziol and Newton (1988) and Spear (1993) (see Supplementary document; available online from https:// doi.org/10.2465/jmps.170923).

If there are paired inclusions of biotite and plagioclase, the $P-T$ condition can be determined as a single point by solving a simultaneous equation: Eqations 1a 
and $1 \mathrm{~b}$. The $P-T$ path can be reconstructed by connecting the sequence of obtained $P-T$ conditions (Fig. 1).

\section{Summary of probabilistic inversion of $P-T$ path}

In practice, there will always be some error and uncertainty deriving from compositional measurements and derivations of the equilibrium and geothermobarometric calibration. Equations 1 can be rewritten with inclusion compositions on the left-hand side as follows:

$$
X_{i}^{\mathrm{Bt}}=f_{\mathrm{Bt}}\left(P_{i}, T_{i}, X_{i}^{\mathrm{Grt}}\right)+\varepsilon_{i}^{\mathrm{Bt}}
$$

and

$$
X_{i}^{\mathrm{Pl}}=f_{\mathrm{Pl}}\left(P_{i}, T_{i}, X_{i}^{\mathrm{Grt}}\right)+\varepsilon_{i}^{\mathrm{Pl}}
$$

where $\varepsilon_{i}^{\mathrm{Bt}}$ and $\varepsilon_{i}^{\mathrm{Pl}}$ are the noise in the mineral composition for measurement point $i$. This noise accounts for measurement errors on $X_{i}^{\mathrm{Bt}}$ and $X_{i}^{\mathrm{Pl}}$ and also includes the composition measurement noise from the host garnet and uncertainties in the derivation of equilibrium and geothermobarometric calibration. In this study, the phlogopite composition $X_{\mathrm{Mg}}^{\mathrm{Bt}}$ and anorthite composition $X_{\mathrm{an}}$ are used for $X^{\mathrm{Bt}}$ and $X^{\mathrm{Pl}}$, respectively.

For inclusion geothermobarometry, we have to consider the inversion problem, which estimates the target parameters (pressure $\boldsymbol{P}$ and temperature $\boldsymbol{T}$ ) from the chemical compositions, $\boldsymbol{X}^{\mathrm{Bt}}$ and $\boldsymbol{X}^{\mathrm{Pl}}$. The vectors $\boldsymbol{P}, \boldsymbol{T}$, $\boldsymbol{X}^{\mathrm{Bt}}$, and $\boldsymbol{X}^{\mathrm{Pl}}$ respectively indicate the sequential set of variables $P, T, X^{\mathrm{Bt}}$, and $X^{\mathrm{Pl}}$ for all measurement points $i=1, \ldots, N$. Owing to noise and uncertainty, probabilistic treatment is required for geothermobarometric calibration. We now consider Bayesian probabilistic estimations of $P-T$ paths from observed mineral compositions.

Bayesian inference is based on a posterior distribution $p\left(\boldsymbol{P}, \boldsymbol{T} \mid \boldsymbol{X}^{\mathrm{Bt}}, \boldsymbol{X}^{\mathrm{Pl}}\right)$, which is the conditional probability of the target parameters (pressure $\boldsymbol{P}$ and temperature $\boldsymbol{T}$ ) given the observed mineral compositions $\boldsymbol{X}^{\mathrm{Bt}}$ and $\boldsymbol{X}^{\mathrm{Pl}}$. In inversion analysis, the $P-T$ path that maximizes the posterior probability $p\left(\boldsymbol{P}, \boldsymbol{T} \mid \boldsymbol{X}^{\mathrm{Bt}}, \boldsymbol{X}^{\mathrm{Pl}}\right)$ is considered to be the most probable solution for the available dataset and available information about the prior $P-T$ path. Bayes' theorem states that

$$
p\left(\boldsymbol{P}, \boldsymbol{T} \mid \boldsymbol{X}^{\mathrm{Bt}}, \boldsymbol{X}^{\mathrm{Pl}}\right)=\frac{p\left(\boldsymbol{X}^{\mathrm{Bt}}, \boldsymbol{X}^{\mathrm{Pl}} \mid \boldsymbol{P}, \boldsymbol{T}\right) p(\boldsymbol{P}, \boldsymbol{T})}{p\left(\boldsymbol{X}^{\mathrm{Bt}}, \boldsymbol{X}^{\mathrm{Pl}}\right)}
$$

where is the likelihood function, which is the generation probability of the mineral compositions $\boldsymbol{X}^{\mathrm{Bt}}$ and $\boldsymbol{X}^{\mathrm{Pl}}$ given the target parameters $\boldsymbol{P}$ and $\boldsymbol{T}$, and $p(\boldsymbol{P}, \boldsymbol{T})$ indicates the prior probability of pressure $\boldsymbol{P}$ and temperature $\boldsymbol{T}$, which is the probability of the event before the collection of new data.

Bayes' theorem (Eq. 3) is considered to relate back to the law of causality by tracing the result from the cause. In contrast to posterior probability, the likelihood function and prior probability can be formulated relatively easily because they have the same direction - that is, the forward direction - as the law of causality that is the basis of our logical thinking. In this study, the likelihood function is formulated by using Equation 2 as the forward model, and the noise, $\varepsilon_{i}^{\mathrm{Bt}}$ and $\varepsilon_{i}^{\mathrm{Pl}}$ is assumed to fit a Gaussian distribution having a mean of zero and variance $\sigma_{\mathrm{Bt}}^{2}$ and $\sigma_{\mathrm{Pl}}^{2}$, respectively. Following Kuwatani et al. (2012), we adopt the Gaussian Markov chain as the prior probability in order to introduce the continuity of pressure and temperature. In the Gaussian Markov chain, the variance of the magnitude of the respective gaps in $P$ and $T$ between two adjacent points is $\sigma_{\Delta P}^{2}$ and $\sigma_{\Delta T}^{2}$, respectively. A detailed explanation of the likelihood function and prior probability is provided in the Supplementary document.

For mathematical simplicity, we define the evaluation function as the negative logarithm of the posterior probability: The minimization of the evaluation function, $E(\boldsymbol{P}, \boldsymbol{T})$, is equivalent to the maximization of the posterior probability, $p\left(\boldsymbol{P}, \boldsymbol{T} \mid \boldsymbol{X}^{\mathrm{Bt}}, \boldsymbol{X}^{\mathrm{Pl}}\right)$, owing to the monotonicity of the logarithmic function. The defined prior probabilities and likelihood functions are substituted into Bayes' theorem (Eq. 3). The evaluation function can thus be obtained as follows:

$$
\begin{aligned}
E(\boldsymbol{P}, \boldsymbol{T} ; \boldsymbol{\theta}) \equiv & -\ln p\left(\boldsymbol{P}, \boldsymbol{T} \mid \boldsymbol{X}^{\mathrm{Bt}}, \boldsymbol{X}^{\mathrm{Pl}}\right) \\
= & \frac{1}{2 \sigma_{\mathrm{Bt}}^{2}} \sum_{N_{\mathrm{Bt}}}\left(f_{\mathrm{Bt}}\left(P_{i}, T_{i}, X_{i}^{\mathrm{Grt}} s\right)-X_{i}^{\mathrm{Bt}}\right)^{2} \\
& +\frac{1}{2 \sigma_{\mathrm{Pl}}^{2}} \sum_{N_{\mathrm{Pl}}}\left(f_{\mathrm{Pl}}\left(P_{i}, T_{i}, X_{i}^{\mathrm{Grt}} s\right)-X_{i}^{\mathrm{Pl}}\right)^{2} \\
& +\frac{1}{2 \sigma_{\Delta P}^{2}} \sum_{i=1}^{N-1}\left(P_{i+1}-P_{i}\right)^{2} \\
& +\frac{1}{2 \sigma_{\Delta T}^{2}} \sum_{i=1}^{N-1}\left(T_{i+1}-T_{i}\right)^{2}+C(\boldsymbol{\theta})
\end{aligned}
$$

where $\boldsymbol{\theta}$ denotes the set of hyperparameters $\left\{\sigma_{\mathrm{Bt}}^{2}, \sigma_{\mathrm{Pl}}^{2}\right.$, $\left.\sigma_{\Delta P}^{2}, \sigma_{\Delta T}^{2}\right\}$. The summation of $\sum_{N_{\mathrm{Bt}}}$ and $\sum_{N_{\mathrm{Pl}}}$ indicates the summation of measurement points where biotite and plagioclase inclusions exist, and $C(\boldsymbol{\theta})$ indicates a function of $\boldsymbol{\theta}$, which is a constant independent of $(\boldsymbol{P}, \boldsymbol{T})$ (see Supplementary document).

The evaluation function consists of three parts: (1) the first and second terms indicate the reproducibility of 
Table 1. Chemical compositions used in this study

\begin{tabular}{|c|c|c|c|c|c|c|c|c|c|}
\hline \multirow[t]{2}{*}{ Position } & \multicolumn{2}{|c|}{ Biotite } & \multicolumn{4}{|c|}{ Garnet } & \multirow{2}{*}{$\begin{array}{c}\text { Plagioclase } \\
X_{\text {an }}\end{array}$} & \multicolumn{2}{|c|}{$P-T$} \\
\hline & $X_{\mathrm{Fe}}$ & $X_{\mathrm{Mg}}$ & $X_{\mathrm{Fe}}$ & $X_{\mathrm{Mg}}$ & $X_{\mathrm{Mn}}$ & $X_{\mathrm{Ca}}$ & & $P(\mathrm{GPa})$ & $T\left({ }^{\circ} \mathrm{C}\right)$ \\
\hline$\# 1$ (core) & 0.411 & 0.589 & 0.711 & 0.146 & 0.013 & 0.127 & 0.218 & 0.927 & 525.9 \\
\hline$\# 2$ & 0.414 & 0.586 & 0.708 & 0.155 & 0.012 & 0.120 & 0.218 & 0.961 & 550.5 \\
\hline$\# 3$ & 0.414 & 0.586 & 0.710 & 0.162 & 0.010 & 0.114 & 0.262 & 0.909 & 561.6 \\
\hline$\# 4$ & 0.430 & 0.570 & 0.720 & 0.159 & 0.010 & 0.105 & 0.273 & 0.889 & 571.4 \\
\hline$\# 5$ & 0.489 & 0.509 & 0.720 & 0.126 & 0.031 & 0.121 & 0.347 & 0.865 & 575.0 \\
\hline \#6 & 0.491 & 0.507 & 0.718 & 0.126 & 0.031 & 0.121 & 0.359 & 0.860 & 578.3 \\
\hline$\# 7$ & 0.491 & 0.507 & 0.720 & 0.123 & 0.032 & 0.123 & 0.359 & 0.848 & 569.0 \\
\hline$\# 8$ & 0.492 & 0.507 & 0.703 & 0.110 & 0.059 & 0.125 & 0.395 & 0.766 & 538.2 \\
\hline \#9 (rim) & 0.492 & 0.507 & 0.710 & 0.113 & 0.052 & 0.123 & 0.395 & 0.771 & 543.6 \\
\hline
\end{tabular}

These data are taken from Sample \#6 garnet in Table 4 of St-Onge (1987).

Also listed are pressure and temperature estimates that were calibrated deterministically using geothermometry (Ferry and Spear, 1978) and geobarometry (Koziol and Newton, 1988).

the observed compositions; (2) the third and fourth terms reflect the continuity of pressure and temperature; and (3) other terms depend on their variance and noise variance, but are independent of the target parameters $(\boldsymbol{P}, \boldsymbol{T})$. The set of pressure $\boldsymbol{P}$ and temperature $\boldsymbol{T}$ that minimizes $E(\boldsymbol{P}, \boldsymbol{T}$; $\boldsymbol{\theta})$ is the most probable estimation that satisfies the requirements for both the reproducibility of the observed compositions and the continuity of the $P-T$ path.

Before minimizing the evaluation function, we must appropriately determine the hyperparameters $\boldsymbol{\theta}$. As described in Supplementary document, these hyperparameters can be determined by minimizing the free-energy function $F(\boldsymbol{\theta})$ defined by the negative logarithm of the posterior probability $p\left(\boldsymbol{\theta} \mid \boldsymbol{X}^{\mathrm{Bt}}, \boldsymbol{X}^{\mathrm{Pl}}\right)$. In this study, these hyperparameter sets are determined using the steepest descent method with the Markov chain Monte Carlo (MCMC) method (Metropolis et al., 1953). In addition to minimizing the free-energy function, the MCMC calculations yield two solution sets: a maximum a posteriori (MAP) solution set $(\boldsymbol{P}, \boldsymbol{T})$ that minimizes the evaluation function (Eq. 4); and a posterior mean (PM) solution, which is an alternative solution set defined by the mean value of a number of candidate sets over the posterior distribution, calculated by the sampling algorithm from the posterior distribution.

\section{DESCRIPTION OF DATASETS}

To verify the validity and effectiveness of the proposed model, we tested the described probabilistic inversion method for estimating $P-T$ paths with actual compositional datasets consisting of host and inclusion minerals. We used host garnet and inclusion biotite and plagioclase compositions from lower Proterozoic pelitic schists in the Wopmay Orogen, Canada, published by St-Onge (1987). The interior of the Wopmay Orogen is characterized by metamorphic zonation that ranges in metamorphic grade from the chlorite zone to the sillimanite-K-feldspar zone, toward a suite of syntectonic granitoid intrusives. The data are well suited for the purpose of evaluating our proposed model, because host garnets include abundant inclusion minerals, and post-entrapment compositional modification by diffusion and discontinuous growth have not been reported (St-Onge, 1987). Sample \#6 garnet from Table 4 of St-Onge (1987) is used in this study (Table 1).

Figure 2a shows compositional profiles for biotite and plagioclase inclusions and for the zoned garnet host from core to rim. The spessartine component remains approximately constant in the core, and increases from mantle to rim, suggesting reverse zoning. Overall, the almandine and pyrope components increase very slightly, and then decrease from core to rim. For inclusion minerals, the annite component of biotite and the anorthite content of plagioclase both increase from core to rim. Figure $2 \mathrm{~b}$ shows the $P-T$ path calibrated from previous deterministic inclusion geothermobarometry. In this study, we used the garnet-biotite geothermometer by Ferry and Spear (1978) and the GASP geobarometer by Koziol and Newton (1988) (see Supplementary document). Ideal mixing activity models were assumed for both geothermobarometers according to Spear (1993). These assumptions were made in order to simplify the mathematical formulations and to focus the discussion on the evaluation of the proposed probabilistic inversion framework. Kyanite was used as the aluminosilicate mineral, because kyanite was detected in both the pelite matrix and as inclusions, and the overall $P-T$ path lies within the kyanite stability field (St-Onge, 1987). The temperature increased from 525 to $590{ }^{\circ} \mathrm{C}$ and then decreased to $540{ }^{\circ} \mathrm{C}$. The pressure increased from 0.92 to $0.97 \mathrm{GPa}$ before decreasing to $0.77 \mathrm{GPa}$. 


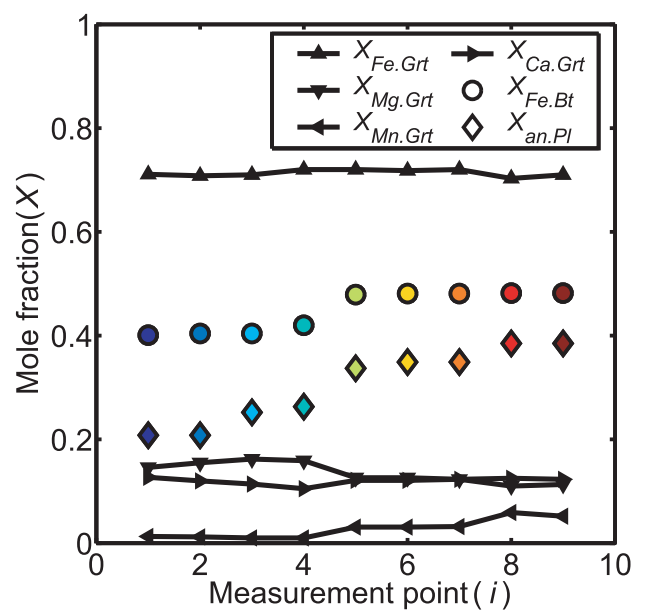

(a) Mineral compositions

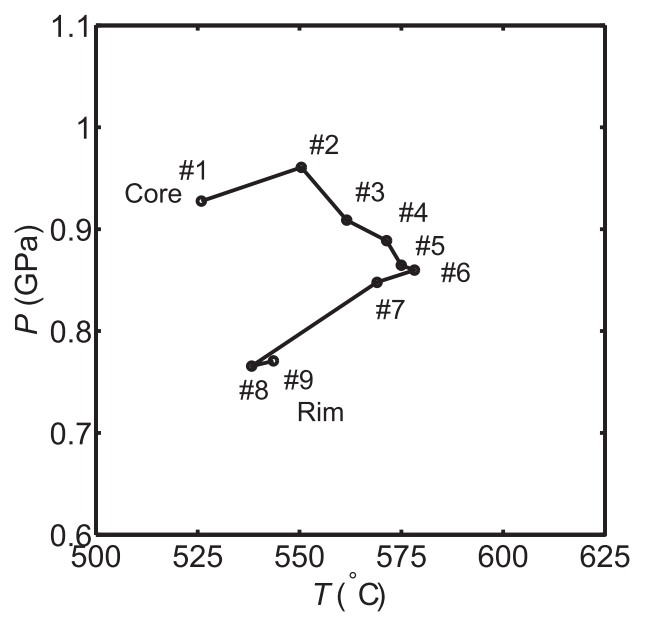

(b) Calibrated $P-T$ paths

Figure 2. (a) Host garnet and inclusion biotite and plagioclase mineral compositions, from core to rim (Table 1). Upward-, downward-, left-, and right-pointing triangles indicate almandine, pyrope, spessartine, and grossular content in host garnet, respectively. Circles and diamonds indicate the compositions of inclusion biotite and plagioclase, respectively. Symbol color indicates the number of measurement points from core to rim. (b) Deterministic $P-T$ paths calibrated with the garnet-biotite geothermometer and the GASP geobarometer using mineral compositions. Numbered points correspond to measurement points in (a).

Although small differences exist between the new calibration and that of the original presented in St-Onge (1987), the trend and overall shape of the $P-T$ path is almost the same as that obtained using the Hodges and Spear (1982) geothermometer and geobarometer. St-Onge (1987) obtained similar clockwise $P-T$ loops for seven samples from different localities using inclusion geothermobarometry. St-Onge interpreted these paths as the product of crustal thickening followed by uplift and erosion, consistent with the model proposed by England and Thompson (1984).

\section{PROBABILISTIC INVERSION OF P-T PATHS}

We applied the probabilistic inversion method for determining $P-T$ paths to the mineral composition datasets of St-Onge (1987). To consider general $P-T$ path inversion problems in natural metamorphic rocks, we also included calculations for several cases in which part of the inclusion was randomly removed. Inversion tests were conducted for the following three cases: Case 1 used all inclusion data; Cases 2 and 3 used ten inclusions (about half of the data) and five inclusions (about a quarter of the data). These tests allow us to investigate how effectively the proposed method reconstructs the $P-T$ path in cases of insufficient information.

\section{Case 1: Using all inclusion data}

First, we present the results for Case 1, which uses all the inclusion data, corresponding to the case in which a host mineral includes abundant inclusions suitable for both geothermometry and geobarometry. Biotite and plagioclase inclusions coexist for all measurement points, enabling us to define a single $P-T$ condition for each point. Therefore, this case is taken as the standard case against which all other cases are compared.

Figure 3 shows the estimated hyperparameters plotted against the iteration count calculated with the steepest descent method. As the iteration count increased, the increments of estimated values decreased to zero. In addition, we tested the stable convergence for different initial hyperparameter settings, and this indicated that no local minima exist that might affect the analysis. The standard deviations of the continuity of pressure $\sigma_{\Delta P}$ and temperature $\sigma_{\Delta T}$ converge to $13.1{ }^{\circ} \mathrm{C}$ and $0.031 \mathrm{GPa}$, respectively (Table 2). The standard deviations of compositional noises $\sigma_{\mathrm{Bt}}$ and $\sigma_{\mathrm{Pl}}$ are 0.0046 and 0.0070 , respectively, consistent with the analytical uncertainties inherent in the individual microprobe mineral analyses (St-Onge, 1987).

Figure $4 \mathrm{a}$ shows the estimated $P-T$ paths of the MAP and PM solutions for $(\boldsymbol{P}, \boldsymbol{T})$ in Case 1 . The $P-T$ path calculated numerically by solving Equation 1, hereafter referred to as the deterministic method, is shown in Figure 4 for the sake of comparison. The MAP and PM $P-T$ paths are almost the same as those calibrated deterministically. This result indicates that when each measurement point can be used to define a single $P-T$ condition, the probabilistic method gives the same solution as the deterministic method based on the compositional data. Fig- 
ure 4b shows all candidate points for $(\boldsymbol{P}, \boldsymbol{T})$ generated with the MCMC sampling algorithm from the posterior probability for each measurement point. The candidate points are distributed elliptically around each PM $P-T$ point, forming a cloud of probability. This means that the pro-

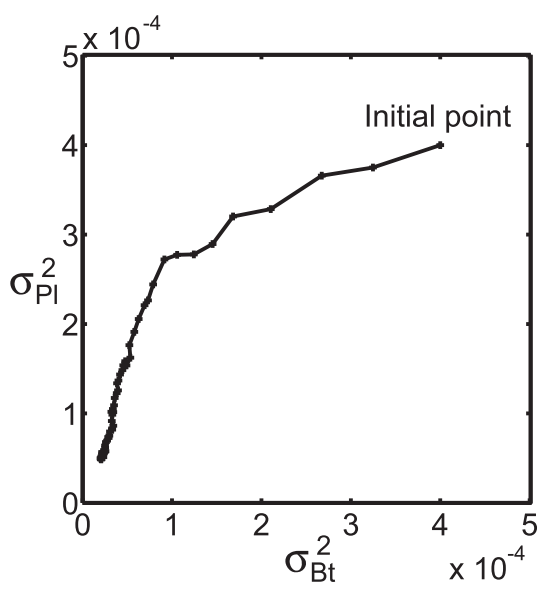

(a) $\sigma_{\mathrm{Pl}}^{2}-\sigma_{\mathrm{Bt}}^{2}$

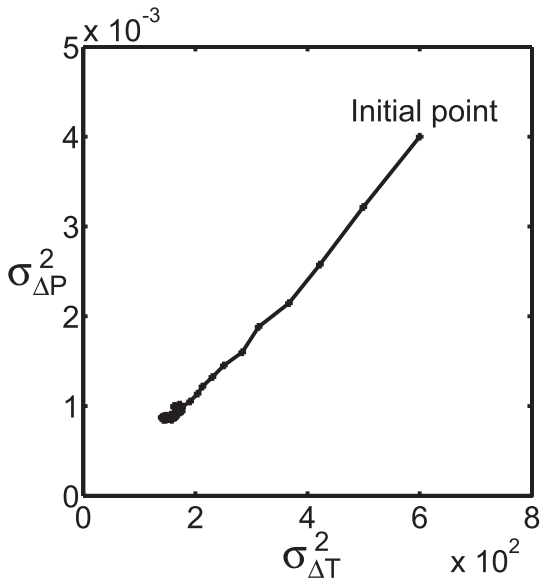

(b) $\sigma_{\Delta P}^{2}-\sigma_{\Delta T}^{2}$

Figure 3. Hyperparameter evolution calculated with the steepest descent method, Case 1. posed method not only estimates the single most probable $P-T$ path, but also evaluates the errors of that path.

\section{Case 2: Using approximately half of the inclusion da- taset}

To consider common $P-T$ path inversion problems in natural metamorphic rocks, we calculated several cases in which the number of inclusions is small (Fig. 5a). In these cases, biotite and plagioclase inclusions do not always closely coexist. Because we cannot depict two reaction curves for each measurement point, the $P-T$ condition cannot be determined as a single point.

Figure 5a shows the chemical composition of the host garnet and the biotite and plagioclase inclusions for Case 2. The number of inclusions is 10; approximately half of the biotite and plagioclase inclusions were randomly removed from the original inclusion dataset (Fig. $2 a)$. Figure $5 b$ shows the reaction curve using the equilibrium relation between host garnet and available inclusions for each measurement point. For measurement points $\# 2$, \#6, and \#9, biotite and plagioclase inclusions coexist, such that pressure and temperature can be determined as the point at the intersection of the two reaction curves. For the other measurement points, there is only one reaction curve: either the geothermometer for biotite, or the geobarometer for plagioclase. Consequently, it is difficult to estimate the overall $P-T$ path quantitatively and objectively using the deterministic method.

For probabilistic $P-T$ path estimation, two approaches were employed considering the problem of hyperparameter estimation. The first approach (Case 2-1) involved estimating the hyperparameters for both noise and continuity variance in the same manner as for Case 1. The estimated continuity variance was slightly larger than the values obtained for Case 1, but it was generally consistent with Case 1, as listed in Table 2. On the other hand, the noise variance was observed to converge to zero. This is considered artificial, because any compositional data will have more or less measurement noise and

Table 2. Hyperparameters estimated using the steep descent method in each case

\begin{tabular}{|c|c|c|c|c|}
\hline \multirow[t]{2}{*}{ Cases } & \multicolumn{2}{|c|}{ Compositional noise } & \multicolumn{2}{|c|}{ Continuity of $P$ and $T$} \\
\hline & $\sigma_{\mathrm{Bt}}$ & $\sigma_{\mathrm{PI}}$ & $\sigma_{\Delta T}\left({ }^{\circ} \mathrm{C}\right)$ & $\sigma_{\Delta P}(\mathrm{GPa})$ \\
\hline 1. Using all data & 0.0046 & 0.0070 & 13.1 & 0.031 \\
\hline 2-1. Using approximately half of the data & 0 & 0 & 16.7 & 0.042 \\
\hline 2-2. Id. with assumed noise variance & $(0.0030)$ & $(0.0030)$ & 15.2 & 0.041 \\
\hline 3-1. Using approximately one-quarter of the data & 0 & 0 & 15.8 & 0.041 \\
\hline 3-2. Id. with assumed noise variance & $(0.0030)$ & $(0.0030)$ & 20.2 & 0.057 \\
\hline
\end{tabular}

The standard deviations and square root of the variance, for compositional noise and continuity, are listed. Numbers with brackets indicate assumed parameters. 


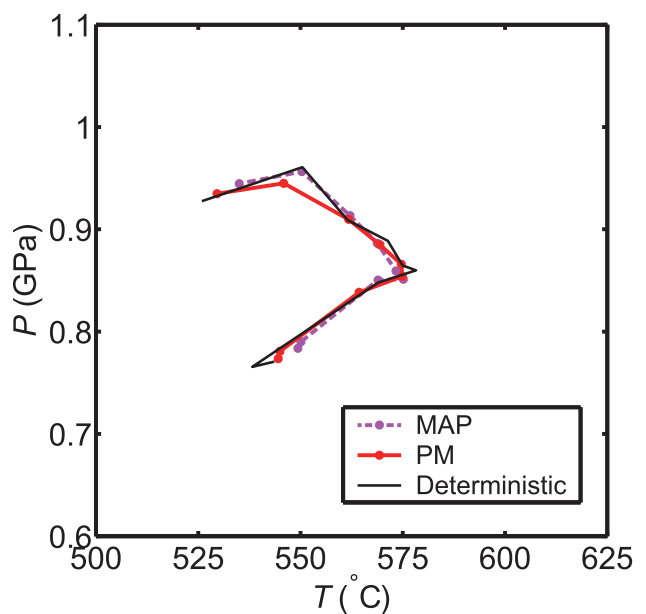

(a) MAP and PM estimations for Case 1

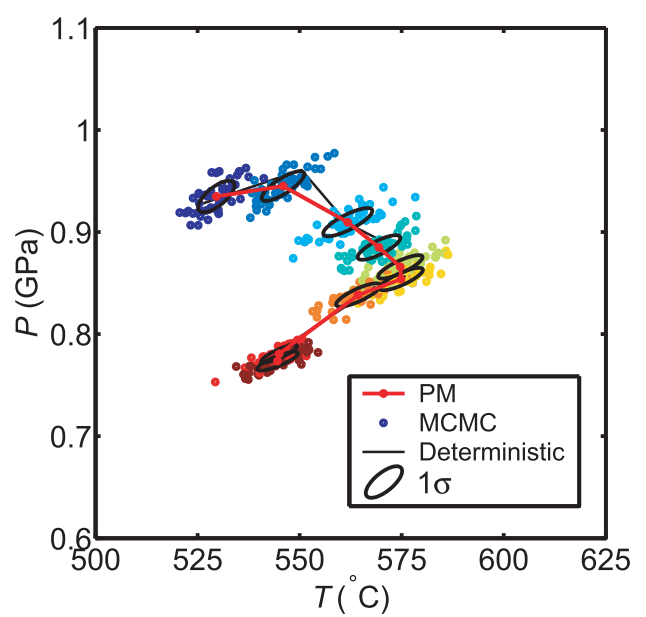

(b) $\mathrm{PM}$ and sampling points for Case 1

Figure 4. Estimated $P-T$ paths using the MRF method for Case 1 , for which all inclusions were used. The previously estimated deterministic $P-T$ path is shown for comparison. In (a), the MAP (a maximum a posteriori) and PM (posterior mean) estimates are shown. In (b), the candidate $P-T$ conditions sampled by the MCMC method are shown for each measurement point. Also shown is the $1 \sigma P-T$ region, which is estimated using the candidate sample points, for each measurement point. Point color indicates the number of measurement points from core to rim, which is the same as in Figure 2.

uncertainty. The failure of hyperparameter estimation is probably the result of smaller measurement points. The noise and continuity variance hyperparameters lie in the deeper hierarchy relative to mineral compositions and pressure and temperature; hyperparameter estimation generally requires a large amount of data. Indeed, whereas the hyperparameter estimation might fail, the obtained $P-T$ path was roughly similar to Case 1 and Case $2-1$, as shown in Figure S1a (Fig. S1 is available online from https://doi.org/10.2465/jmps.170923). By contrast, for measurement points where biotite and plagioclase coexist $(\# 2, \# 6$, and $\# 9)$, there were no $1 \sigma$ errors, because all candidate $P-T$ conditions converged on the $P-T$ conditions estimated with the deterministic method (Fig. S1b).

Unlike with the first approach (Case 2-1), where noise variance converged to zero, we exclusively estimated hyperparameters for continuity variance (Case 2-2). In this case, the noise variance was assumed to be a fixed value $\left(\sigma_{\mathrm{Bt}}^{2}, \sigma_{\mathrm{Pl}}^{2}\right)=\left(0.003^{2}, 0.003^{2}\right)$. The noise variance assumption is considered to be reasonable because, in general, prior information is available for compositional noise compared with continuity variance $\sigma_{\Delta P}^{2}$ and $\sigma_{\Delta T}^{2}$ for the $P-T$ path. The estimated continuity variances are presented in Table 2, and they are consistent with Cases 1 and $2-1$.

Consequently, we obtained a continuous $P-T$ path calculated by the MAP and PM solution shown in Figure $5 c$. The shape of both estimated paths is roughly similar to the deterministic one obtained using the complete inclusion dataset. The PM solution is smoother than the MAP solution in each case, because the fluctuations in each path were canceled out by summing all of the candidate estimates. Figure $5 \mathrm{~d}$ shows the $1 \sigma$ uncertainties calculated by candidate sets that were sampled with the MCMC algorithm for Case 2-1, with the assumed noise variance. The size and direction of $1 \sigma$ uncertainty varied from point to point, according to coexistence of inclusions. In order to investigate its effect, we checked the distribution of candidate sets for some measurement points.

Figure 6 shows a histogram illustrating the probability distributions of $P$ and $T$ for measurement points \#2-5. For measurement point $\# 2$, this case is considered to be well constrained, because biotite and plagioclase coexist for this measurement point (Fig. 6a). The mode value corresponds approximately to the PM and MAP solutions, and it is almost identical to the deterministic solution. The shape of the probabilistic distributions for $P$ and $T$ is a sharp single peak. Similarly, for measurement points where biotite and plagioclase coexist (\#2, \#6, and \#9), $1 \sigma P-T$ uncertainty conditions were focused on the $P-T$ points estimated with the deterministic method (Fig. 5d).

When either biotite or plagioclase inclusions were absent, candidate $P-T$ conditions were dispersed along the reaction curves depicted by the equilibrium of host garnet and inclusions. For measurement point \#3, where only plagioclase inclusion exists, only the GASP geobarometer was applied, ensuring that the pressure was well constrained rather than the temperature (Fig. 6b). This is similar in the case of measurement point $\# 7$, where $1 \sigma$ 


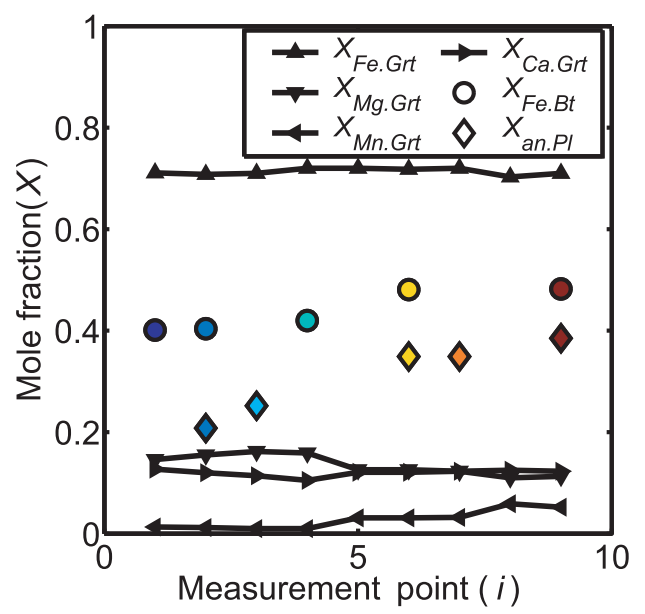

(a) Mineral compositions for Case 2

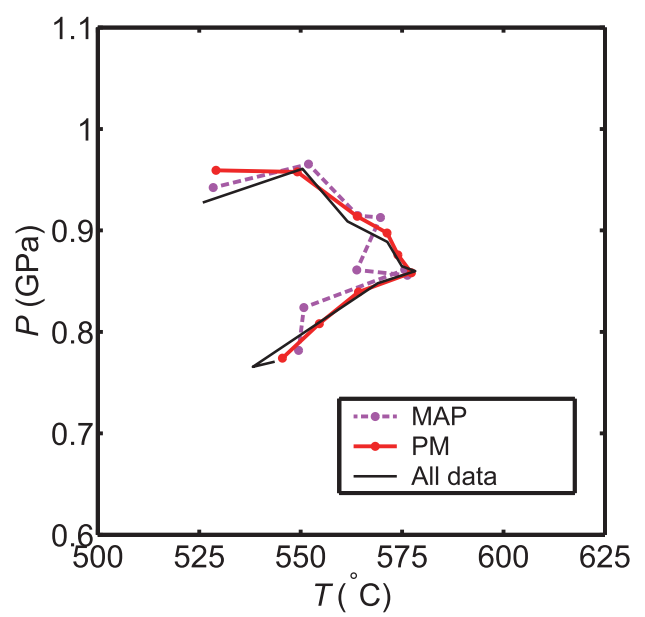

(c) MAP and PM for Case 2-2

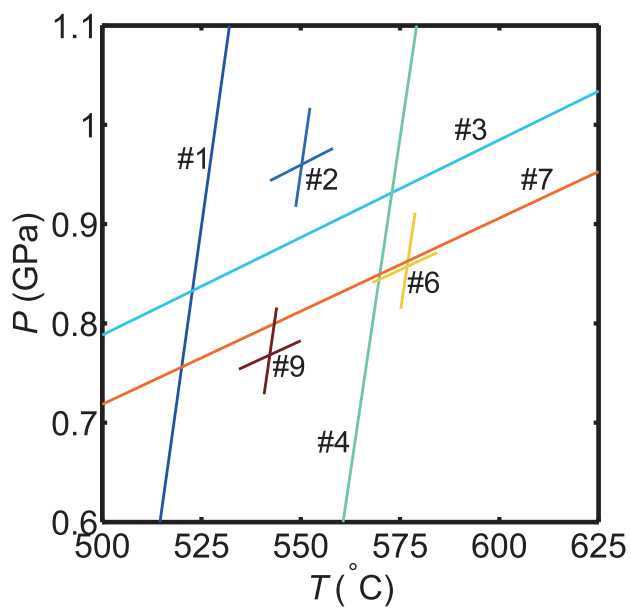

(b) Reaction curves for Case 2

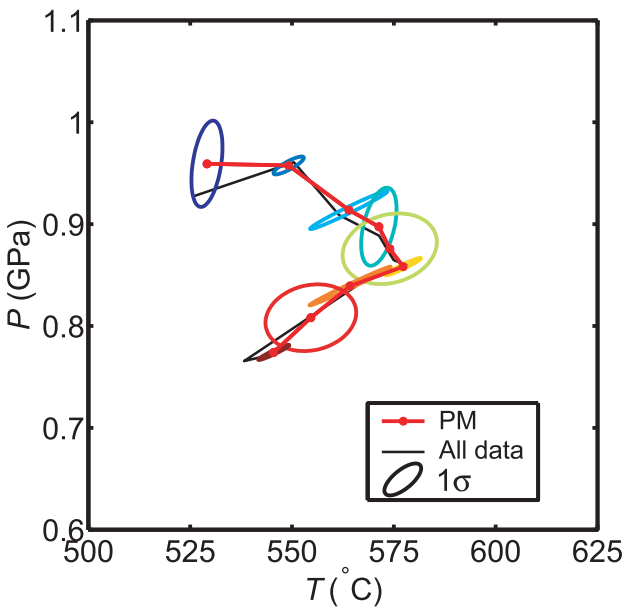

(d) PM and $1 \sigma$ error ellipsoids for Case 2-2

Figure 5. (a) Mineral compositions, (b) reaction curves using host-inclusion mineral equilibria for Case 2 considering 10 inclusions (approximately half of the original data). (c) and (d) Estimated $P-T$ paths for Case 2-2, where the preliminary noise variances are assumed to be fixed values. Using the deterministic method, we can only define $P-T$ conditions if a geothermometer and a geobarometer can be employed for each measurement point (\# 2, 6, and 9) as shown in (b). In (c) and (d), the deterministically estimated $P$ - $T$ path using all inclusion data is shown for comparison.

$P-T$ uncertainty conditions were positioned along the reaction curves of the GASP geobarometer (Fig. 5d). On the other hand, only biotite inclusion exists for measurement point \#4, and the temperature is well constrained using the garnet-biotite geothermometer (Fig. 6c), which is similar in the case of measurement point \#1.

For measurement point \#5, neither plagioclase nor biotite inclusion exists, such that neither the geobarometer nor the geothermometer were applied. The candidates are widely dispersed around the original deterministic point in the $P-T$ space (Fig. 6d). The standard deviations for pressure and temperature were approximately identical to those of temperature for measurement point \#4 and those of pressure for measurement point \#3. Although the size of $1 \sigma$ uncertainty is large, the pressure and temperature could be constrained around the original deterministic point for measurement points \#5 and \#8 (Fig. 5d).

\section{Case 3: Using approximately one quarter of the inclu- sion dataset}

In natural samples, we cannot always find a suitable mineral assemblage series for $P-T$ path estimation. To consider such cases, we calculated an example (Case 3) in which the number of inclusions is insufficient for $P-T$ path estimation. In this case, we assume the host-inclu- 

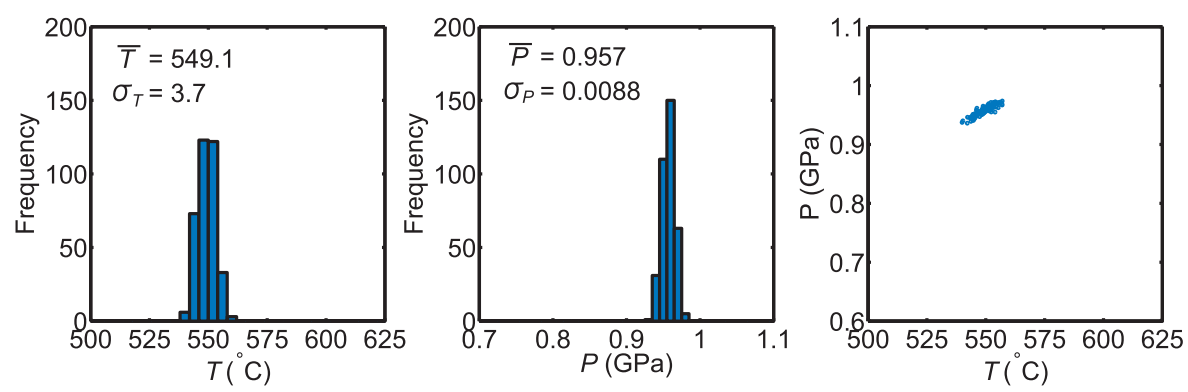

(a) Point \#2 biotite and plagioclase inclusions (standard)
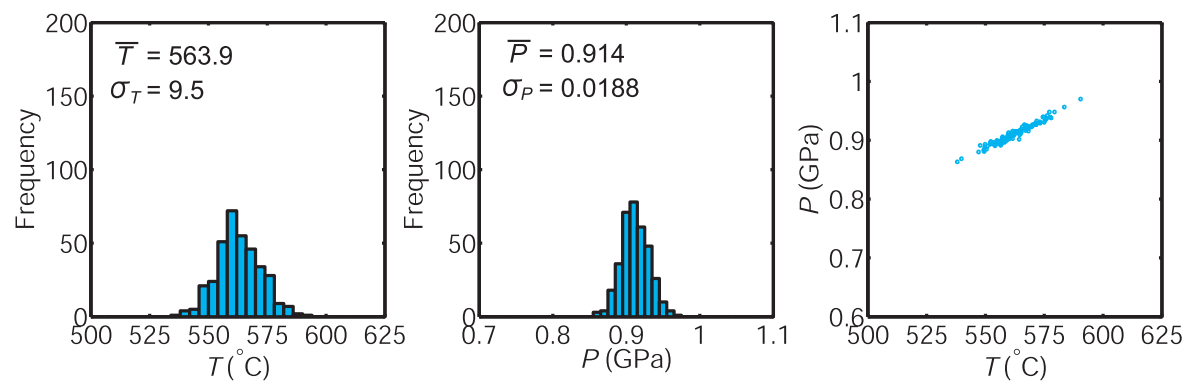

(b) Point \#3, plagioclase inclusion
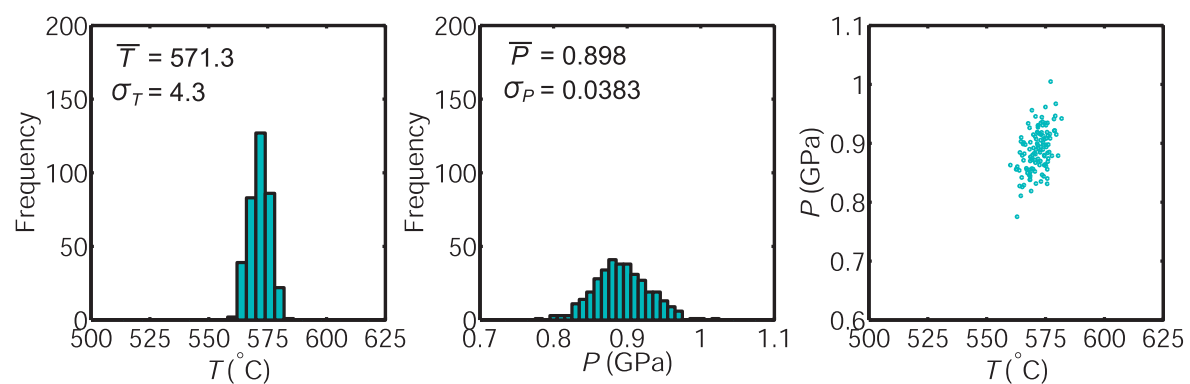

(c) Point \#4, biotite inclusion
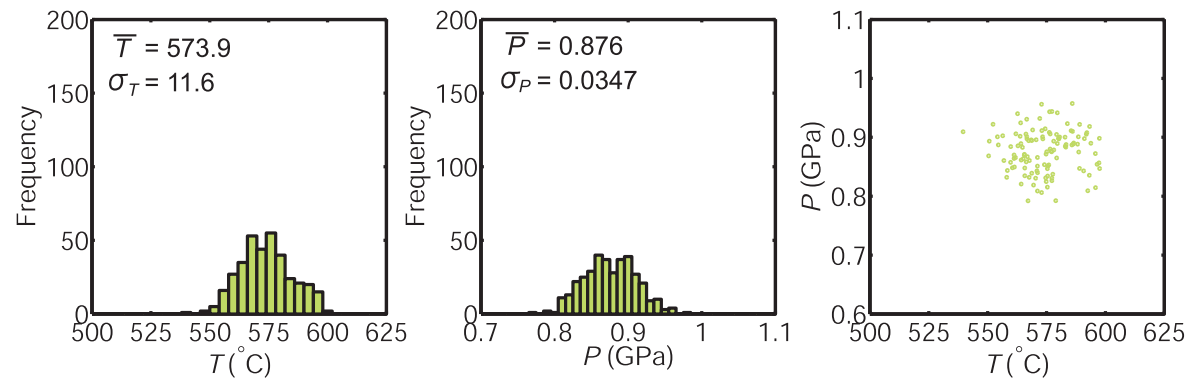

(d) Point \#5, no inclusion

Figure 6. Histograms and $P-T$ regions showing estimated candidates sampled by the MCMC algorithm for measurement points $\# 2-\# 5$ in Case 2. The number of candidates is set to be 360 . Bar color indicates the measurement point, which is the same as in previous figures.

sion assemblages of the points of plagioclase \#2 and \#9, biotite $\# 1, \# 5$, and $\# 9$, and a continuous garnet line profile (Fig. 7a). There were five inclusions, approximately a quarter of the original number of inclusions. By using a conventional deterministic approach, we could reliably calculate $P-T$ conditions only for the analysis of $\# 9$, 


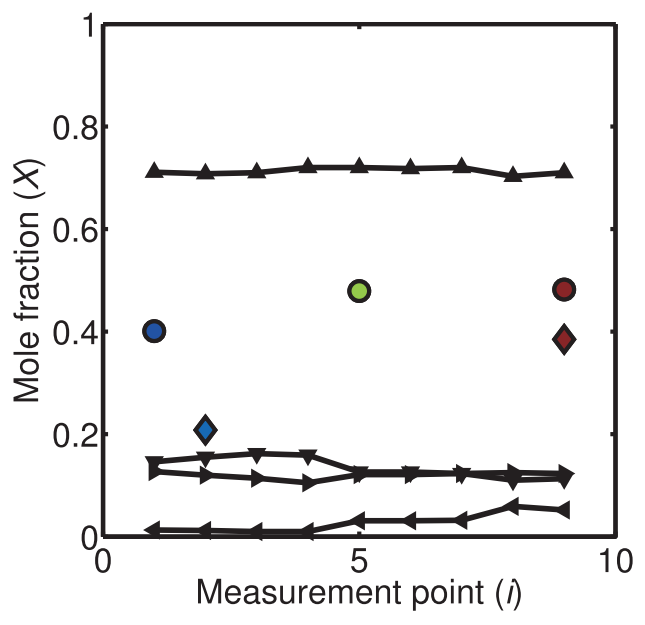

(a) Mineral compositions for Case 3

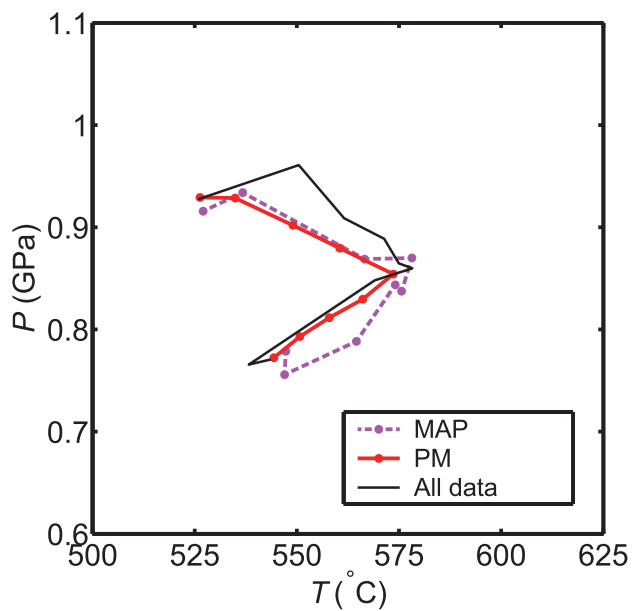

(c) MAP and PM for Case 3-2

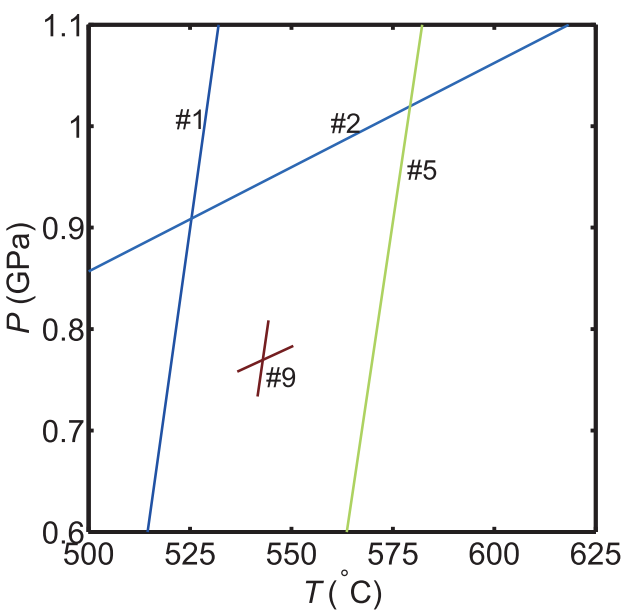

(b) Reaction curves for Case 3

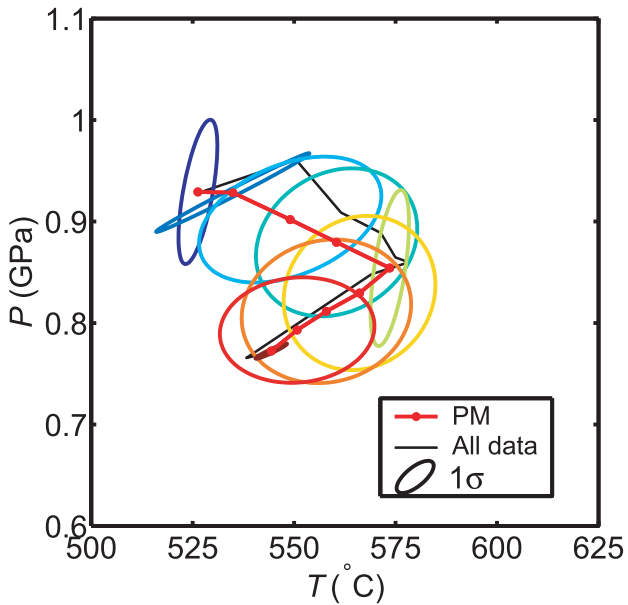

(d) $\mathrm{PM}$ and $1 \sigma$ error ellipsoids for Case 3-2

Figure 7. (a) Mineral compositions, (b) reaction curves using host-inclusion mineral equilibria and the estimated $P$ - $T$ paths for Case 3 for five inclusions (approximately one-quarter of the original data). (c) and (d) Estimated $P-T$ paths for Case 3 , where the preliminary noise variances are assumed to be fixed values. Using the deterministic method, we can only define $P-T$ conditions if a geothermometer and a geobarometer can be employed for each measurement point (\# 9). The deterministically estimated $P$ - $T$ path using all inclusion data is shown for comparison.

and this was merely a fortunate case. On the other hand, the other three points (viz., \#1, \#2, and \#5) provided either pressure or temperature information (Fig. 7b), making it difficult to even roughly deduce the $P-T$ path.

The results of hyperparameter estimation are similar to Case 2. In cases where both noise and continuity variance were unknown (Case 3-1), the noise variance converged to zero, and the continuity variance came close to the results in Cases 1 and 2-1 (Table 2). In Case 3-2, we fixed the noise variances at $\left(\sigma_{\mathrm{Bt}}^{2}, \sigma_{\mathrm{Pl}}^{2}\right)=\left(0.003^{2}, 0.003^{2}\right)$, because the lack of noise variance in Case 3-1 is artificial. As a result, the continuity variance was nearly twice as large as that in Case 1. These significantly varied es- timates are probably the result of more flexibility as the result of fewer inclusions.

Figures $7 \mathrm{c}$ and $7 \mathrm{~d}$ respectively show the MAP and PM solutions for Case 3-2 (see also Fig. S1; for Case 3-1). Although the reproducibility of the original deterministic path was slightly lower than in previous cases, the shape of both estimated paths was roughly similar to the deterministic one obtained using the complete inclusion dataset. On the other hand, the peak metamorphic pressure was underestimated compared to the original $P-T$ path. This reflects the small number of data points used, which overemphasized the continuity of $P$ and $T$. The $1 \sigma$ regions of the candidate points were widely dispersed compared 
to Case 2. For example, the width ranged from 0.82 to $0.96 \mathrm{GPa}$ and from 525 to $575{ }^{\circ} \mathrm{C}$ for point \#3, where no inclusion existed. It is notable that the $1 \sigma$ region for each point covered the entire original $P-T$ path. From the above results, the $P-T$ path could be restored probabilistically, despite having only a small amount of inclusions.

\section{DISCUSSION}

\section{Path reconstruction from sparse mineral inclusions}

In general, geothermobarometry is subject to multiple barriers: finding an applicable mineral assemblage in a so-called happy relationship, evaluating whether the original $P-T$ information is preserved, and confirming the timing to which the conditions are attributed. To select suitable mineral assemblages fulfilling these requirements, petrologists have performed detailed petrographic descriptions, finding only a few candidates for $P-T$ estimations. This sparsity makes it challenging to deduce the detailed shape of the $P-T$ path in many cases. The coexistence of inclusion minerals that can be used for both geothermometry and geobarometry is also rare. Thus, defining a precise $P-T$ condition for each measurement point is not always possible. A deterministic approach is thus inappropriate with this type of problem, whereas the proposed Bayesian probabilistic approach enables us to estimate $P-T$ paths quantitatively.

Consequently, we obtained $P-T$ conditions for measurement points that lack either a geothermometer or barometer, and even those that contain no $P-T$-indicative inclusions, as described in the previous section. This means that the proposed method can construct a continuous $P-T$ path, exploiting all available information from the zoned host mineral and corresponding inclusions. The calculated examples shown in Cases 2 and 3 indicate that only a half or even a quarter of the original inclusion dataset can roughly reproduce the entire shape of the $P-T$ path (Figs. 5 and 7).

In Case 3, however, the proposed method failed to estimate the pressure peak conditions, which corresponded to measurement point \#2 (Fig. 2b). In point \#2, plagioclase exists such that geobarometry works, whereas the absence of biotite prevents the use of geothermometry (Fig. 7b), making it difficult to identify the $P-T$ condition. Together with the assumed continuity of pressure and temperature, the proposed model underestimated both pressure and temperature conditions for point \#2 (Fig. 7c).

Although Bayesian probabilistic inversion can be a valuable tool to deduce a concealed structure in the $P-T$ histories from partial information, it is not a magical tool that creates hypothetical peak pressure/temperature stages. Rigid evidence found by conscientious petrographic observation is still required to discover hidden corner points. As demonstrated, the probability variance depends on the information available for a given measurement point and its neighbors. The more information that is available to constrain $P-T$ conditions, the more precise the estimate of the $P-T$ path will be.

The abovementioned example employs $P-T$ estimations of garnet-biotite with a geothermometer and GASP geobarometer. However, the proposed method can be combined with other established geothermobarometers as well. For example, if we found a garnet-muscovite assemblage for the early stage, and a garnet-biotite assemblage for the later stage, we could combine both to construct a $P-T$ path. Any information constraining $P-T$ conditions can be summed up to construct a continuous $P-T$ path. Moreover, discontinuous structures resulting from episodes of resorption and growth hiatuses (among others) could be dealt with by extending the proposed method. In order to represent the discontinuity of a $P-T$ path, additional latent variables that correspond to edges in image processing could be incorporated within the evaluation function (e.g., Geman and Geman, 1984). Further details are discussed by Kuwatani et al. (2012).

\section{Probabilistic estimation of errors}

Using the Bayesian approach, we obtained a single set consisting of the most probable solution and the probability distributions of the possible solutions sampled by the MCMC algorithm. From the obtained probability distributions, we can objectively evaluate the obtained solution. Using the probabilistic distributions, moreover, we can discuss the probability of the estimates. For example, we can estimate the probability of having temperatures in the range of 545 to $555^{\circ} \mathrm{C}$ as $70 \%$ for measurement point \#2 in Case 2-2 (Fig. 6a).

For the deterministic method, using geothermometry and geobarometry, the errors from estimating $P$ and $T$ were calculated using the error propagation law with the assumption of compositional measurement errors and other uncertainties (e.g., Anderson, 1976; Hodges and McKenna, 1987; Kohn and Spear, 1991a, 1991b; Kohn, 1993). The proposed method also assumes measurement errors and other uncertainties in the forward model and estimates probabilistic distributions by propagating the errors using the Monte Carlo technique. Thus, the proposed method intrinsically includes the deterministic method and the error propagation algorithm for error evaluation.

It is notable that the proposed $P-T$ path analysis is novel insofar as it introduces error evaluation on the basis of the continuity of pressure and temperature. Figure 8 

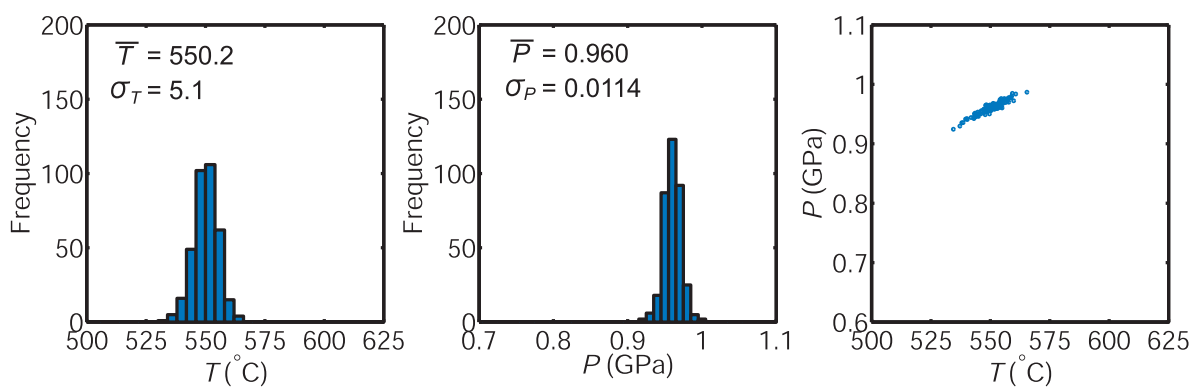

Figure 8. Histograms and $P-T$ regions showing estimated candidates sampled with the MCMC algorithm for measurement point \#2 without continuity of pressure and temperature in Case 2 . In point \#2 biotite and plagioclase inclusions coexist. The continuity of pressure and temperature is not introduced into the analysis. The analysis corresponds to the previous methods for error propagation using the Monte Carlo technique. The number of candidates is set at 360 .

shows histograms for the probability distributions of $P$ and $T$ for measurement point \#2 in a case where noise was assumed, yet continuity variance was set to infinity. This case ignores pressure and temperature continuity, whereas measurement point \#2 in Case 2-2 in Figure 6 a assumes this continuity. The shape of the probabilistic distributions that ignore continuity is closer to a Gaussian distribution than the shape of those that assume continuity. In addition, the variance of both the temperature and pressure candidate datasets is larger than in the case assuming continuity. Thus, pressure and temperature continuity in the proposed MRF method constrains the uncertainty of the $P-T$ estimation.

Probability variance depends on the information available for a given measurement point and its neighbors. The more information available to constrain $P-T$ conditions, the more precise the estimate of the $P-T$ path, as shown in Figure 6. Although this is intuitive, deterministic methods cannot resolve problems associated with this fact. The deterministic method simply evaluates whether or not a problem is solvable. Using the Bayesian approach, we formulated the physical process statistically, enabling us to evaluate the precision of the solution with various constraints on $P-T$ estimates.

\section{CONCLUDING REMARKS}

We developed a probabilistic inversion method to obtain $P-T$ paths using inclusion geothermobarometry by applying an MRF model. With the proposed MRF model, the continuity of pressure and temperature was introduced to the prior probability as Gaussian Markov chains. Using an optimization approach with an evaluation function and the free-energy function, ill-posed problems in which compositional data are insufficient to define $P-T$ conditions at each measurement point can be overcome. To evaluate the proposed model, we applied it to solve $P-T$ inversion problems using a garnet-biotite geothermometer and a garnet- $\mathrm{Al}_{2} \mathrm{SiO}_{5}$-plagioclase-quartz geobarometer, with the inclusion dataset of St-Onge (1987). Our method successfully reconstructed the $P-T$ path, even with a small number of inclusions.

The most valuable aspects of our approach are as follows: (1) $P-T$ paths can be quantitatively estimated using inclusion geothermobarometry, despite the rarity of the coexistence of inclusion minerals that can be applied to both geothermometry and geobarometry; and (2) both a single set of the most probable $P-T$ path and the probability distributions of possible $P-T$ paths can be obtained. The precision of the estimated $P-T$ conditions depends on the amount of available information for each measurement point.

Moreover, this flexible Bayesian formulation can be applied to various inversion problems. In this study, inclusion geothermobarometry was adopted as a forward function regarding mineral compositions and $P-T$ conditions. However, any thermodynamic model can potentially be adopted as a forward function, including the construction of pseudosections (e.g., Powell and Holland, 1988; Connolly, 1990) and differential thermodynamic forward modeling (Kuwatani et al., 2011, Kuwatani and Toriumi, 2017). By making assumptions about the bulk composition, all mineral compositions can be defined by inputting $P-T$ conditions. By using a statistical approach, forward thermodynamic modeling can be incorporated into inversion analysis, to enable the reconstruction of $P-T$ paths for a wide variety of metamorphic systems.

\section{ACKNOWLEDGMENTS}

We thank two anonymous reviewers for constructive comments. This work was supported by JST PRESTO (Grant Numbers JPMJPR1676 and JPMJPR15E8), JST CREST (Grant Number JPMJCR1761), JSPS KAKENHI (Grant Numbers JP25120005, JP25120009, JP25280090, and JP15K20864), and the Cooperative Research Pro- 
gram of the Earthquake Research Institute, University of Tokyo (2015-B04).

\section{SUPPLEMENTARY MATERIALS}

Supplementary document and Figure S1 are available online from https://doi.org/10.2465/jmps.170923.

\section{REFERENCES}

Anderson, G.M. (1976) Error propagation by Monte-Carlo method in geochemical calculations. Geochimica et Cosmochimica Acta, 40, 1533-1538.

Bishop, C. (2006) Pattern recognition and machine learning. pp. 738, Springer, New York.

Burenjargal, U., Okamoto, A., Meguro, Y. and Tsuchiya, N. (2012) An exhumation pressure-temperature path and fluid activities during metamorphism in the Tseel terrane, SW Mongolia: Constraints from aluminosilicate-bearing quartz veins and garnet zonings in metapelites. Journal of Asian Earth Sciences, 54-55, 214-229.

Connolly, J.A.D. (1990) Multivariable phase diagrams: an algorithm based on generalized thermodynamics. American Journal of Science, 290, 666-718.

England, P.C. and Thompson, A.B. (1984) Pressure-temperaturetime paths of regional metamorphism. 1.Heat-transfer during the evolution of regions of thickened continental-crust. Journal of Petrology, 25, 894-928.

Ferry, J.M. and Spear, F.S. (1978) Experimental calibration of partitioning of $\mathrm{Fe}$ and $\mathrm{Mg}$ between biotite and garnet. Contributions to Mineralogy and Petrology, 66, 113-117.

Geman, S. and Geman, D. (1984) Stochastic relaxation, Gibbs distributions, and the Bayesian restoration of images. IEEE Transactions on Pattern Analysis and Machine Intelligence, 6, 721-741.

Hodges, K.V. and Spear, F.S. (1982) Geothermometry, geobarometry and the $\mathrm{Al}_{2} \mathrm{SiO}_{5}$ triple point at Mt Moosilauke, NewHampshire. American Mineralogist, 67, 1118-1134.

Hodges, K.V. and McKenna, L.W. (1987) Realistic propagation of uncertainties in geologic thermobarometry. American Mineralogist, 72, 671-680.

Hoisch, T.D., Wells, M.L. and Hanson, L.M. (2002) Pressure-temperature paths from garnet-zoning: Evidence for multiple episodes of thrust burial in the hinterland of the Sevier orogenic belt. American Mineralogist, 87, 115-131.

Inui, M. and Toriumi, M. (2002) Prograde pressure-temperature paths in the pelitic schists of the Sambagawa metamorphic belt, SW Japan. Journal of Metamorphic Geology, 20, 563580.

Jones, K.A. (1994) Progressive metamorphism in a crustal-scale shear zone - an example from the Leon Region, North-West Brittany, France. Journal of Metamorphic Geology, 12, 69-88.

Kohn, M.J. (1993) Uncertainties in differential thermodynamic (Gibbs Method) $P-T$ paths. Contributions to Mineralogy and Petrology, 113, 24-39.

Kohn, M.J. and Spear, F.S. (1991a) Error propagation for barometers. 1. Accuracy and precision of experimentally located end-member reactions. American Mineralogist, 76, 128-137.

Kohn, M.J. and Spear, F.S. (1991b) Error propagation for barometers. 2. Application to rocks. American Mineralogist, 76,
138-147.

Konrad-Schmolke, M. and Halama, R. (2014) Combined thermodynamic-geochemical modeling in metamorphic geology: Boron as tracer of fluid-rock interaction. Lithos, 208-209, 393-414.

Koziol, A.M. and Newton, R.C. (1988) Redetermination of the anorthite breakdown reaction and improvement of the plagioclase-garnet- $\mathrm{Al}_{2} \mathrm{SiO}_{5}$-quartz geobarometer. American Mineralogist, 73, 216-223.

Kuwatani, T., Okamoto, A. and Toriumi, M. (2011) Thermodynamic forward modeling of progressive dehydration reactions during subduction of oceanic crust under greenschist facies conditions. Earth and Planetary Science Letters, 307, 9-18.

Kuwatani, T., Nagata, K., Okada, M. and Toriumi, M. (2012) Precise estimation of pressure-temperature paths from zoned minerals using Markov random field modeling: theory and synthetic inversion. Contributions to Mineralogy and Petrology, $163,547-562$.

Kuwatani, T., Nagata, K., Okada, M. and Toriumi, M. (2014a) Markov random field modeling for mapping geofluid distributions from seismic velocity structures. Earth, Planets and Space, 66, 5:1-5:9.

Kuwatani, T., Nagata, K., Okada, M. and Toriumi, M. (2014b) Markov-random-field modeling for linear seismic tomography. Physical Review E, 90, 042137:1-042137:7.

Kuwatani, T. and Toriumi, M. (2017) Thermodynamic forward modeling of retrogressive hydration reactions induced by geofluid infiltration. Earth, Planets and Space, 69, 18:1-18:10.

Meyer, M., Klemd, R., Hegner, E. and Konopelko, D. (2014) Subduction and exhumation mechanism of ultra-high and highpressure oceanic and continental crust at Makbal (Tianshan, Kazakhstan and Kyrgyzstan). Journal of Metamorphic Geology, 32, 861-884.

Massonne, H.J. (2011) Phase relations of siliceous marbles at ultrahigh pressure based on thermodynamic calculations: examples from the Kokchetav Massif, Kazakhstan and the Sulu terrance. Chinese Journal of Geology, 46, 114-125.

Metropolis, N., Rosenbluth, A.W., Rosenbluth, M.N., Teller, A.H. and Teller, E. (1953) Equation of state calculations by fast computing machines. Journal of Chemical Physics, 21, 10871092.

Mosegaard, K. and Tarantola, A. (1995) Monte Carlo Sampling of Solutions to Inverse Problems. Journal of Geophysical Research, 10, B7, 12,431-12,447.

Okamoto, A. and Toriumi, M. (2001) Application of differential thermodynamics (Gibbs' method) to amphibole zonings in the metabasic system. Contributions to Mineralogy and Petrology, 141, 268-286.

Omori, S., Kita, S., Maruyama, S. and Santosh, M. (2009) Pressure-temperature conditions of ongoing regional metamorphism beneath the Japanese Islands. Gondwana Research, $16,458-469$.

Okudaira, T. (1996) Temperature-time path for the low-pressure Ryoke metamorphism, Japan, based on chemical zoning in garnet. Journal of Metamorphic Geology, 14, 427-440.

Powell, R. and Holland, T.J.B. (1988) An internally consistent thermodynamic dataset with uncertainties and correlations. 3. Application methods, worked examples and a computer program. Journal of Metamorphic Geology, 6, 173-204.

Spear, F.S. (1993) Metamorphic phase equilibria and PressureTemperature-Time paths. Monograph 1, Mineralogical Society of America, Washington, D.C. 
Spear, F.S. and Selverstone, J. (1983) Quantitative $P-T$ paths from zoned minerals - Theory and tectonic applications. Contributions to Mineralogy and Petrology, 83, 348-357.

St-Onge, M.R. (1987) Zoned poikiloblastic garnets - $P-T$ paths and syn-metamorphic uplift through $30-\mathrm{Km}$ of structural depth, Wopmay Orogen, Canada. Journal of Petrology, 28, 121.

Tanaka, K. (2002) Statistical-mechanical approach to image processing. Journal of Physics A: Mathematical and General, 35, R81-R150.

Vignaroli, G., Rossetti, F., Bouybaouene, M., Massonne, H.J., Theye, T., Faccenna, C. and Funiciello, R. (2005) A counter-clockwise $P-T$ path for the Voltri Massif eclogites (Ligur- ian Alps, Italy). Journal of Metamorphic Geology, 23, 533555.

Whitney, D.L. and Ghent, E.D. (1993) Prograde reactions and garnet zoning reversals in staurolite schist, British-Columbia Significance for thermobarometric interpretations. Journal of Metamorphic Geology, 11, 779-788.

Yardley, B.W.D. (1977) An empirical study of diffusion in garnet. American Mineralogist, 62, 793-800.

Manuscript received September 23, 2017

Manuscript accepted February 22, 2018

Published online April 19, 2018

Manuscript handled by M. Satish-Kumar 